\title{
The kinetic competition between transport and oxidation of ferrous ions governs precipitation of corrosion products in carbonated concrete
}

\author{
Matteo Stefanonia*, Zhidong Zhang ${ }^{\mathrm{a}}$, Ueli Angst ${ }^{\mathrm{a}}$, Bernhard Elsener ${ }^{\mathrm{a}, \mathrm{b}}$ \\ a Institute for Building Materials, ETH Zurich, Zurich 8093, Switzerland \\ ${ }^{b}$ University of Cagliari, Department of Chemical and Geological Science, Monserrato I-09100 (CA), Italy
}

Received: 23 April 2018 / Accepted: 06 September 2018 / Published online: 14 September 2018

(c) The Author(s) 2018. This article is published with open access and licensed under a Creative Commons Attribution 4.0 International License.

\begin{abstract}
Corrosion products, originating from steel corrosion in carbonated concrete and precipitating in the concrete pore system, can lead to cracking and spalling of the concrete cover. To avoid this common form of structural deterioration and thus ensure durable structures, reliable quantitative models are needed. Here, we present a new conceptual model to describe the fate of ferrous ions that are released at the steel surface during the corrosion process. The key novelty can be found in explicitly considering the kinetics of oxidation and transport of Fe ${ }^{2+}$ in the pore solution. These two processes constantly dilute the $\mathrm{Fe}^{2+}$ concentration and are in competition with the supply of $\mathrm{Fe}^{2+}$ from the anodic iron dissolution reaction. We use a numerical model to elucidate which of the described processes is the fastest. The results find good agreement with experimental data and reveal that under natural corrosion conditions, $\mathrm{Fe}^{2+}$ hardly reaches the saturation level, which permits the diffusion of corrosion products up to millimetres away from the steel without necessarily leading to expansive stresses. Under accelerated corrosion conditions, however, in a chloride-free environment, precipitation is accelerated immediately at the steel surface. This changes the corrosion products precipitation distribution and suggests careful evaluation of accelerated tests and related models.
\end{abstract}

Keywords: Diffusion; Iron solubility; Accelerated corrosion; Steel-concrete interface

\section{Introduction}

Reinforced concrete structures undergo a variety of degradation processes, among which corrosion-induced damages are the most common cause of deterioration [1, 2]. Therefore, the prediction of the event of corrosion induced concrete cover cracking due to precipitation of corrosion products is of key importance in service life prediction and structural design $[3,4]$. The phenomenon has been studied and modeled through a variety of approaches. The laboratory experimentation of such process is limited by the very long time that it takes, for natural corrosion process, to get to such an advanced state, leading to the concrete cover cracking. That is why the process is generally accelerated by impressed current methods, which enhances the corrosion rate of steel embedded in concrete [5-10], and therefore enhances the formation of corrosion products. On the other hand, the process has been extensively modeled using a variety of approaches and computing techniques. The deterioration depends on the type of corrosion mechanism, that is, corrosion being of uniform (carbonation induced) or localized (chloride induced) morphology [11]. Modeling studies typically considered corrosion induced cracking as a consequence of a uniform volume expansion of the steel rebar, which arises from the uniform formation of corrosion products on the steel surface, building up pressure against the concrete surrounding the steel $[3,5,7,12-16]$. This assumption of a uniform volume expansion is certainly a strong simplification, as it has been experimentally found that, even in case of uniform corrosion, the formation of corrosion products can be non-uniformly distributed in the concrete matrix [5]. Nevertheless, a common model approach is to introduce a so-called "corrosion accommodation region" $[5,12]$ which is thought to be a porous cement paste layer around the steel bar, into which corrosion products can be pushed and no pressure is assumed to be exerted to the concrete until this porous zone is filled $[7,13,16]$. This concept allows to empirically model the time delay between the first release of corrosion

* Corresponding author: Matteo Stefanoni, E-mail: matteost@ethz.ch 
products and the beginning of pressure build up, which is typically observed in experimental studies.

Modeling approaches consider instantaneous precipitation of corrosion products quantified by Faraday's law [3]. This assumption of simple "expansion" of the steel bars, due to the positive volumetric difference between corrosion products and iron in metallic state (factor 2 to 6$)[1,17]$, is based on assuming immediate precipitation of the iron oxides directly at the steel surface. This hypothesis has been confirmed in strongly accelerated corrosion experiments by microscopy analysis of the steel concrete interface, where a thick and dense layer of corrosion products could be found between the steel and the cementitious matrix $[5,6,10]$.

In this letter, the approach so far described is analyzed based on electrochemical and physico-chemical considerations, supported by literature evidences. We consider corrosion in carbonated, chloride-free concrete. The influence of chlorides, where iron solubility is increased by the formation of iron-chloride complexes [18] is left for further consideration. Our results show that - in natural, as opposed to accelerated, corrosion conditions - it is unlikely that the primary product of the corrosion redox reaction $\left(\mathrm{Fe}^{2+}\right)$ reaches saturation. It is suggested that the ferrous ions have the possibility to diffuse into the cementitious matrix before further oxidation and precipitation occurs.

\section{Formation of corrosion products}

The formation of corrosion products is a necessary step in corrosion induced concrete cracking. In case of chloride contaminated environment the solubility of these products is enhanced by the formation of soluble iron-chloride complexes $[18,19]$, whereas in carbonated condition it is usually assumed that corrosion products are instantaneously precipitating at the interface [11], due to the low solubility of iron oxides at the $\mathrm{pH}$ characteristic of carbonated conditions $(\mathrm{pH} \approx 8-9)$ [20]. In the modeling approaches mentioned earlier, the assumption is that the corrosion rate represents as well the rate of corrosion products formation at the interface (Faraday's law). The basic electrochemical reactions of the steel corrosion process have been described since the beginning of $20^{\text {th }}$ century [21], which also applies to concrete [22]. The steel dissolution process is the transition from metallic state to a bivalent oxidation state of the iron atom (eq. 1):

$$
F e \rightarrow F e^{2+}+2 e^{-}
$$

However, in studies characterizing the composition of carbonation induced corrosion products formed in concrete, or in other situations such as atmospheric corrosion of steel, the corrosion products have always been found to be composed of compounds with iron in the oxidation state +3 [23-26]. This is because there is an intermediate transformation, that is the spontaneous and fast oxidation reaction of $\mathrm{Fe}^{2+}$ ions, which involves oxygen and hydroxyl ions and leads to the final formation of $\mathrm{Fe}^{3+}$ (eq. 2) $[19,24]$.

$$
\mathrm{Fe}^{2+} \rightarrow \mathrm{Fe}^{3+}+e^{-}
$$

While $\mathrm{Fe}^{3+}$ oxides and hydroxides are highly insoluble (solubility $\approx 10^{-10} \mathrm{M}$, depending on $\mathrm{pH}$, Fig. 1) $[20,27]$ and cause practically instantaneous precipitation upon formation, $\mathrm{Fe}^{2+}$ hydroxide $\left(\mathrm{Fe}(\mathrm{OH})_{2}\right)$ can be significantly more soluble (around $10^{-2}$ to $10^{-4} \mathrm{M}$, depending on pH, Fig. 1) [20, $28,29]$. This means that for corrosion products to precipitate, the $\mathrm{Fe}^{2+}$ ions released in reaction (eq. 1) must either first be oxidized to $\mathrm{Fe}^{3+}$ (eq. 2) (because then the sparingly soluble iron III corrosion products precipitate instantaneously), or the saturation level of $\mathrm{Fe}^{2+}$ must be reached in the concrete pore solution (because then iron II corrosion products precipitate). Reaching the $\mathrm{Fe}^{2+}$ saturation level in the pore solution is, however, inhibited by i) the oxidation of $\mathrm{Fe}^{2+}$ and ii) the continuous transport of $\mathrm{Fe}^{2+}$ away from the steel surface. These two processes constantly dilute the $\mathrm{Fe}^{2+}$ concentration, at a given, limited rate. However, these two processes are in constant competition with the supply of $\mathrm{Fe}^{2+}$ at the steel surface from the anodic iron dissolution reaction (eq. 1). The crucial question to be answered is thus which of the described processes is the fastest. To elucidate this, we present in the next section a numerical model taking into account the described reaction and transport processes.

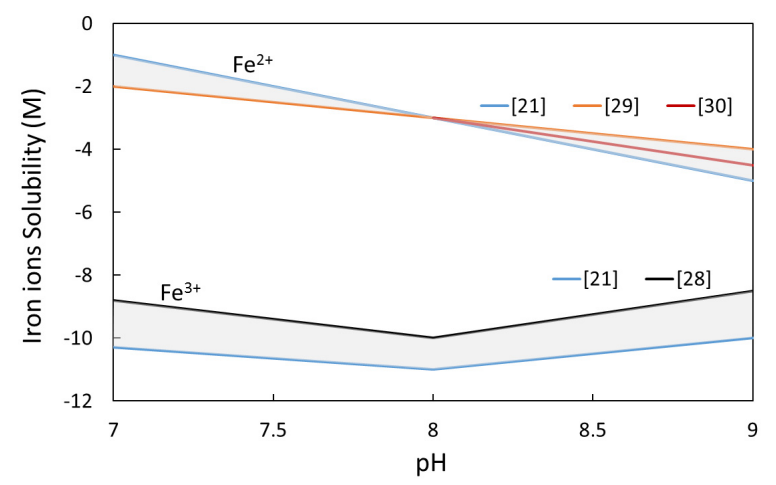

Figure 1. Solubility of $\mathrm{Fe}^{2+}$ and $\mathrm{Fe}^{3+}$ species in the $\mathrm{pH}$ range of carbonated concrete, according to the indicated literature references, illustrating that $\mathrm{Fe}^{3+}$ is much less soluble than $\mathrm{Fe}^{2+}$.

\section{Modeling transport and precipitation of released iron ions in concrete under natural corrosion conditions}

\subsection{Description of the model}

Here, we propose a model to describe the fate of ferrous ions when released into the concrete during the corrosion process. In this chapter, we consider natural corrosion conditions, that is, corrosion rates that are not accelerated by artificial means (the latter will be addressed in section 5). The following steps are considered in the model, schematically illustrated in Fig. 2:

A. Anodic iron dissolution (eq. 1) leading to release of $\mathrm{Fe}^{2+}$ at a given rate. This is the complete corrosion reaction:

$$
2 \mathrm{Fe}+\mathrm{O}_{2}+2 \mathrm{H}_{2} \mathrm{O} \rightarrow 2 \mathrm{Fe}^{2+}+4 \mathrm{OH}^{-}
$$

Here we assume the upper range of corrosion rates observed in carbonated concrete, which is $1 \cdot 10^{-6} \mathrm{~A} / \mathrm{cm}^{2}$ 
in water-saturated conditions as was reported in a wide number of studies $[30,31]$. The rationale is to consider the most severe iron releasing condition expected in natural (not accelerated) corrosion conditions. In states of lower moisture contents, the corrosion rate can be orders of magnitudes lower, thus the release of $\mathrm{Fe}^{2+}$ into the system would be much slower.

B. Direct precipitation of $\mathrm{Fe}^{2+}$ according to the reaction

$$
\mathrm{Fe}^{2+}+2 \mathrm{OH}^{-} \rightarrow \mathrm{Fe}(\mathrm{OH})_{2}
$$

This reaction is assumed to occur immediately (at infinitely high rate) when the saturation level of $\mathrm{Fe}^{2+}$ $\left(1 \cdot 10^{-3} \mathrm{M}\right)$ is overcome.

C. Oxidation of $\mathrm{Fe}^{2+}$ to $\mathrm{Fe}^{3+}$. The kinetics of this reaction step is crucial for the model, as the rate at which $\mathrm{Fe}^{2+}$ can be oxidized is in competition with the rate at which $\mathrm{Fe}^{2+}$ is supplied at the steel surface (anodic dissolution) and the rate at which $\mathrm{Fe}^{2+}$ is transported by diffusion. The kinetics of $\mathrm{Fe}^{2+}$ oxidation are discussed in more detail below.

D. Precipitation of $\mathrm{Fe}^{3+}$, which is here assumed to occur immediately (at infinitely high rate) when the saturation level of $\mathrm{Fe}^{3+}$ is overcome. Note that the solubility of $\mathrm{Fe}^{3+}$ oxides is extremely low (ca. 1·10-10 M) [20] (Fig. 1).

E. Transport of $\mathrm{Fe}^{2+}$ through the pore system of the concrete. Here, we assume that this transport is governed by diffusion following Fick's laws, and that no significant contribution to the transport comes from migration and convection (see below for a more detailed discussion of these assumptions). Moreover, we assume that the porous system starts immediately from the steel surface, has quasi-infinite length, homogenous porosity and initial concentration of iron ions equal to 0 . Further details are discussed below. We acknowledge that the assumption of homogeneity is a strong simplification because it is well known that the steel-concrete interface is not homogeneous, e.g. in terms of porosity [32]. However, we believe that the assumption made here is on the conservative side and is adequate for the illustration of the proposed scientific concept.

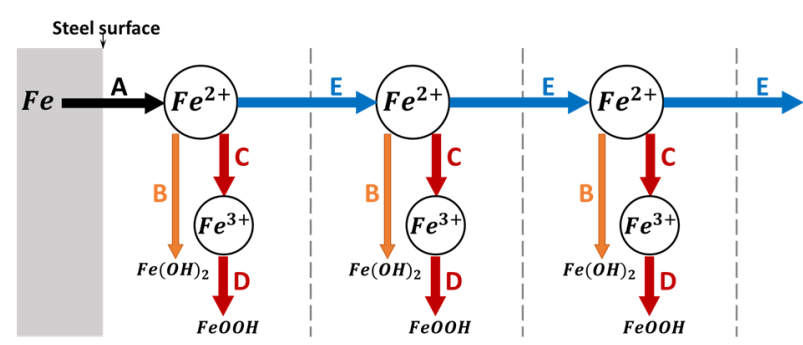

Figure 2. Schematic representation of the model reaction path (steps A to E) from steel corrosion to formation of solid corrosion products in the (water filled) pore system of concrete. The dashed vertical lines represent imaginary vertical slices of the concrete, illustrating the chosen finite element model approach in this work, to predict the concentrations of the different species as a function of both time and distance from the steel surface.
For step (A), given the here assumed corrosion current density of $1 \cdot 10^{-6} \mathrm{~A} / \mathrm{cm}^{2}$, it is possible to define the quantity of $\mathrm{Fe}^{2+}$ released per unit steel area in 1 second (eq. 3, Fig. 2) as a flux across the steel-concrete interface:

$$
J\left(F e^{2+}\right)=1 \cdot 10^{-7} \mathrm{~mol} / \mathrm{s} \cdot \mathrm{m}^{2}
$$

Step (C) describes the oxidation of $\mathrm{Fe}^{2+}$ by the aqueous dissolved oxygen, a process that is usually neglected in corrosion induced cracking, but that has also been extensively studied in water research since the early 60 s [33, 34]. Reviews of the studies on kinetics of ferrous ions oxidation by $\mathrm{O}_{2}$ tried to comprehensively merge the knowledge of oxidation kinetics in order to express the process in terms of its controlling parameters, such as $\mathrm{pH}$ and forms of $\mathrm{Fe}^{2+}$ bearing compounds [28, 35]. Morgan and Lahav [28] showed how, at pH higher than 8 (as in carbonated concrete), the oxidation reaction kinetics are not pH dependent.

Thus, in carbonated concrete, the oxidation (eq. 2) rate can be considered as only dependent on $\left[\mathrm{Fe}^{2+}\right]$ and amount of dissolved oxygen $\left[\mathrm{O}_{2}\right]_{\text {aq }}$ (eq. 7).

$$
\frac{-d\left[\mathrm{Fe}^{2+}\right]}{d t}=k\left[\mathrm{Fe}^{2+}\right]\left[\mathrm{O}_{2}\right]_{a q}
$$

With $k$ kinetic constant, which over the years has been studied, resulting in values spanning over two orders of magnitude (from $15 \mathrm{~s}^{-1} \cdot \mathrm{M}^{-1}$ [35] to $400 \mathrm{~s}^{-1} \cdot \mathrm{M}^{-1}$ [28], calculated as per constant $\mathrm{O}_{2}$ partial pressure, 0.2 bar). The $\mathrm{pH}$ was assumed constant over the entire simulation domain, as it would be buffered by the cement pore solution chemistry. Typical $\mathrm{pH}$ range for carbonated concrete is from 7.2 [36] to 9.5 [37], in this case the $\mathrm{pH}$ was assumed to be $8\left(\mathrm{Fe}^{2+}\right.$ solubility, $\left.1 \cdot 10^{-3} \mathrm{M}\right)$. The kinetic constant of the ferrous iron oxidation reaction $(k$, eq. 7$)$ has been varied around the interval found in literature $\left(2.5,15\right.$ and $\left.100 \mathrm{~s}^{-1} \cdot \mathrm{M}^{-1}\right)$.

Step (E) describes the transport of $\mathrm{Fe}^{2+}$ ions by diffusion. No reliable studies are available for the diffusion properties of $\mathrm{Fe}^{2+}$ in concrete at the best of our knowledge. Thus, we will here take the diffusion coefficient of chlorides $\left(\mathrm{Cl}^{-}\right)$as reference, as the transport properties of chloride ions in concrete are intensively studied. The intrinsic diffusion coefficient of $\mathrm{Cl}^{-}$in water is ca. $1 \cdot 10^{-5} \mathrm{~cm}^{2} / \mathrm{s}$, while in concrete the $\mathrm{Cl}^{-}$effective diffusion coefficient $\left(D_{\text {eff }}\right)$ has been measured to be between ca. $1 \cdot 10^{-8} \mathrm{~cm}^{2} / \mathrm{s}$ and $2 \cdot 10^{-7}$ [38-41]. The same proportionality has been assumed to hold for $\mathrm{Fe}^{2+}$. Starting from its intrinsic diffusion coefficient in water $\left(7 \cdot 10^{-6}\right.$ $\mathrm{cm}^{2} / \mathrm{s}$ ), the $\mathrm{Fe}^{2+}$ effective diffusion coefficient in concrete has been assumed as $1 \cdot 10^{-7} \mathrm{~cm}^{2} / \mathrm{s}$, applying the same proportionality. In the model, the $\mathrm{Fe}^{2+}$ effective diffusion coefficient was varied $\left(1 \cdot 10^{-6}, 1 \cdot 10^{-7}\right.$ and $\left.1 \cdot 10^{-8} \mathrm{~cm}^{2} / \mathrm{s}\right)$ in order to assess its influence on the species concentration and to simulate the possible effect of a denser or more open pore structure.

Liquid advection is not considered in this model, since moisture saturated condition is assumed in this study. Migration of ions as an additional transport mechanism is not included in the model based on the assumption that the ionic strength of pore solution in a carbonated system is still 
relatively high [36], thus even $\mathrm{Fe}^{2+}$ concentration at saturation level $\left(1 \cdot 10^{-3} \mathrm{M}\right)$ can be considered negligible in terms of ionic strength. The authors of this letter extracted pore solution from four different fully carbonated samples (Table 1). The extraction has been performed by means of an hydraulic press, applying a pressure up to $300 \mathrm{MPa}$ for a time comprised between 30 minutes and 3 hours. The data agrees with what was found in literature [36] and the ionic strength is about 100 times higher compared to $\mathrm{Fe}^{2+}$ saturation $\left(1 \cdot 10^{-3} \mathrm{M}\right)$ (Table 1$)$.

Table 1. Composition of pore solution extracted from fully carbonated $\left(4 \% \mathrm{CO}_{2}\right)$ and water saturated samples obtained from ICP analysis.

\begin{tabular}{|l|l|l|l|l|l|}
\hline Mix & $\begin{array}{l}\mathrm{Ca} \\
(\mathrm{g} / \mathrm{l})\end{array}$ & $\begin{array}{l}\mathrm{K} \\
(\mathrm{g} / \mathrm{l})\end{array}$ & $\begin{array}{l}\mathrm{Na} \\
(\mathrm{g} / \mathrm{l})\end{array}$ & $\begin{array}{l}\mathrm{S} \\
(\mathrm{g} / \mathrm{l})\end{array}$ & $\begin{array}{l}\text { lonic strength } \\
(\mathrm{M})\end{array}$ \\
\hline CEM I, 0.5 & 0.744 & 0.590 & 0.128 & 0.624 & 0.086 \\
\hline CEM I, 0.6 & 0.742 & 0.580 & 0.126 & 0.700 & 0.091 \\
\hline CEM II, 0.5 & 0.754 & 0.654 & 0.186 & 0.636 & 0.090 \\
\hline CEM II, 0.6 & 0.698 & 0.656 & 0.332 & 0.792 & 0.100 \\
\hline
\end{tabular}

In summary, the present model considers the following species: $\mathrm{Fe}^{2+} ; \mathrm{Fe}(\mathrm{OH})_{2} ; \mathrm{FeOOH} ; \mathrm{O}_{2}$.

To solve the above described diffusion-reaction problem, a 1D finite element model with two modules - diffusion and chemical reaction - was implemented in COMSOL Multiphysics. The model setup is based on the schematic drawing in Fig. 2, as $\mathrm{Fe}^{2+}$ is released from the rebar on the left and directly diffuses into concrete perpendicular to the rebar surface. The length of the simulation domain is $2 \mathrm{~mm}$ which is clearly longer than the corrosion products penetration depth generally observed in the literature in case of chloride-free conditions (e.g., Fig. 6).

\subsection{Modeling results}

The simulations show that the stationary state of concentrations of dissolved species is achieved within few hours, even at a distance of $1 \mathrm{~mm}$ from the steel surface (Fig. 3). Thus, to illustrate the spatial distribution of $\mathrm{Fe}^{2+}$ in the pore solution of the concrete, Figs. 4 and 5 detail model results obtained at $t=50 \mathrm{~h}$. The differences between the plots shown in Figs. 4 and 5 can be found in different combinations of assumed $\mathrm{Fe}^{2+}$ oxidation kinetics $(\mathrm{k})$ and ferrous ion diffusion coefficients $\left(D_{\text {eff }}\right)$. This permits to analyze the competition between the different processes shown in Fig. 2, namely release (step A), oxidation (step C), and diffusive transport (step $\mathrm{E}$ ) of $\mathrm{Fe}^{2+}$.

As expected, the concentration of $\mathrm{Fe}^{2+}$ at the steel surface is depressed if both oxidation and diffusion are fast. It is one of the key results of this study that even for a fast corrosion rate (the here assumed rate represents the upper range of what can be expected under natural, non-accelerated conditions) the solubility threshold of $\mathrm{Fe}^{2+}$ is never reached, which means that there is no formation of solid $\mathrm{Fe}^{2+}$ corrosion products $\left(\mathrm{Fe}(\mathrm{OH})_{2}\right)$. While the $\mathrm{Fe}^{2+}$ concentration at the steel surface varies between $1 \cdot 10^{-5}$ and $1 \cdot 10^{-4} \mathrm{M}$, depending on the assumed $k$ and $D_{\text {eff, }}$ even the assumption of slow oxidation kinetics and low ferrous ion diffusion coefficient, within the range of what can reasonably be expected in concrete, will lead to $\mathrm{Fe}^{2+}$ concentrations approx. one order of magnitude lower than the solubility threshold (Figs. 4 and 5).

Concerning the spatial distribution of ferrous ion in the concrete, the model confirms the expectations that i) fast oxidation kinetics depress the $\mathrm{Fe}^{2+}$ concentration everywhere in the concrete (because this is a general sink term), and ii) fast diffusion shifts the $\mathrm{Fe}^{2+}$ to larger distances from the steel surface. The distribution of relevant $\mathrm{Fe}^{2+}$ ion concentrations spans over a range of up to hundreds of microns, depending on the input parameters, therefore the region of interest is not restricted to the steel surface zone (Fig. 3 to 5). From the here presented simulation, it can be seen that, using an intermediate kinetic constant $\mathrm{k}$ (15 $\left.\mathrm{M}^{-1} \cdot \mathrm{s}^{-1}\right)$ and $\mathrm{D}_{\text {eff }}\left(1 \cdot 10^{-7} \mathrm{~cm}^{2} / \mathrm{s}\right)$, ca. $20 \%$ of the $\mathrm{Fe}^{2+}$ present at the steel surface is able to diffuse over $10 \mu \mathrm{m}$ (Fig. 3) and ca. $1 \%$ of the $\mathrm{Fe}^{2+}$ ions, is even able to reach $100 \mu \mathrm{m}$ distance (Fig. 3), while only about $0.01 \%$ can reach $1 \mathrm{~mm}$. If the oxidation kinetics are reduced from $\mathrm{k}=100 \mathrm{M}^{-1} \cdot \mathrm{s}^{-1}$ to $\mathrm{k}=2.5$ $\mathrm{M}^{-1} \cdot \mathrm{s}^{-1}$ the concentration of $\mathrm{Fe}^{2+}$ at $100 \mu \mathrm{m}$ increases almost 40 times (Fig. 3 and 4a). While, considering different diffusion properties, when $D_{\text {eff }}$ is increased from $1 \cdot 10^{-8} \mathrm{~cm}^{2} / \mathrm{s}$ to $1 \cdot 10^{-6} \mathrm{~cm}^{2} / \mathrm{s}$, the amount of $\mathrm{Fe}^{2+}$ ions able to reach $100 \mu \mathrm{m}$ increases by a factor ca. 60 (Fig. 4b). In the extreme cases, when slow oxidation $\left(\mathrm{k}=2.5 \mathrm{M}^{-1} \cdot \mathrm{s}^{-1}\right)$ and fast diffusion ( $D_{\text {eff }}=1 \cdot 10^{-6} \mathrm{~cm}^{2} / \mathrm{s}$ ) case is compared to fast oxidation ( $k=100$ $\mathrm{M}^{-1} \cdot \mathrm{s}^{-1}$ ) and slow diffusion ( $D_{\text {eff }}=1 \cdot 10^{-8} \mathrm{~cm}^{2} / \mathrm{s}$ ), the $\mathrm{Fe}^{2+}$ concentration at $100 \mu \mathrm{m}$ increases of a factor $10^{3}$ (Fig. 5).

\subsection{Considerations on the modeling results}

The proposed model is based on literature data and a number of assumptions. These are:

- Chloride-free, carbonated cementitious matrix;

- Only transport by diffusion is considered;

- Matrix porosity is considered constant from the steel surface into the porous system bulk;

- Precipitation is considered instantaneous when saturation is reached.

The simulations results are supported by experimental findings, as will be shown in the following section. It is worth pointing out that in the present model the corrosion rate is taken into account at its highest value expected in natural corrosion conditions, therefore when precipitation and accumulation at the steel-concrete interface would be the highest. However such situation can only occur in exposure class XC4 (according to European standard EN 206-1) and even then represents only a very limited part of a structure's life time, over which it is much more common to have (extended) periods of lower corrosion rates (due to seasonal exposure climate variations). For a lower corrosion rate, the ferrous ions would have even more time for diffusion and oxidation [17]. 

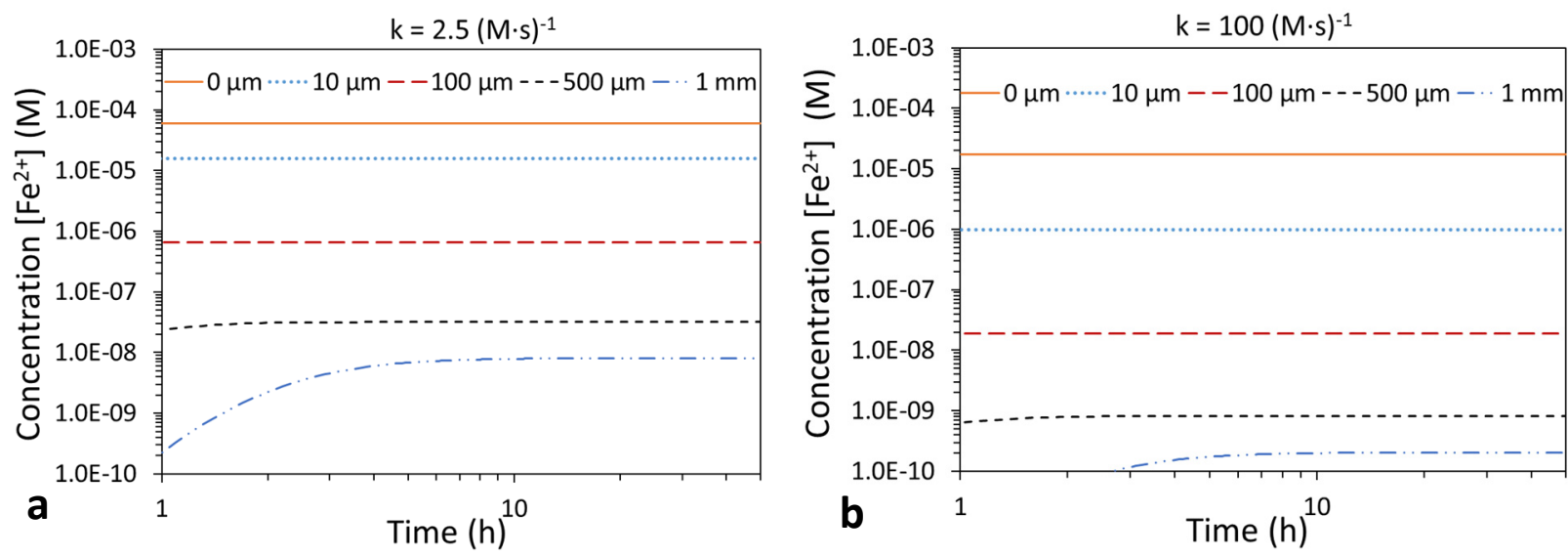

Figure 3. Concentration of Fe $\mathrm{F}^{2+}$ over time, at different distances from the steel surface $(0,10,100,500 \mu \mathrm{m}$ and $1 \mathrm{~mm})$. Process modeled for $\mathrm{D}_{\text {eff }}$ $=1 \cdot 10^{-7} \mathrm{~cm}^{2} / \mathrm{s}$ and different oxidation kinetic constants (eq. 7): a) $\mathrm{k}=2.51 /(\mathrm{M} \cdot \mathrm{s}$ ) (slow), b) $\mathrm{k}=1001 /(\mathrm{M} \cdot \mathrm{s}$ ) (fast). The figures show that after $10 \mathrm{~h}$ the concentration of $\mathrm{Fe}^{2+}$ has achieved the steady state for all considered distances. Also, the results show that a higher Fe ${ }^{2+}$ oxidation rate leads to a lower concentration of $\mathrm{Fe}^{2+}$ at all depths.
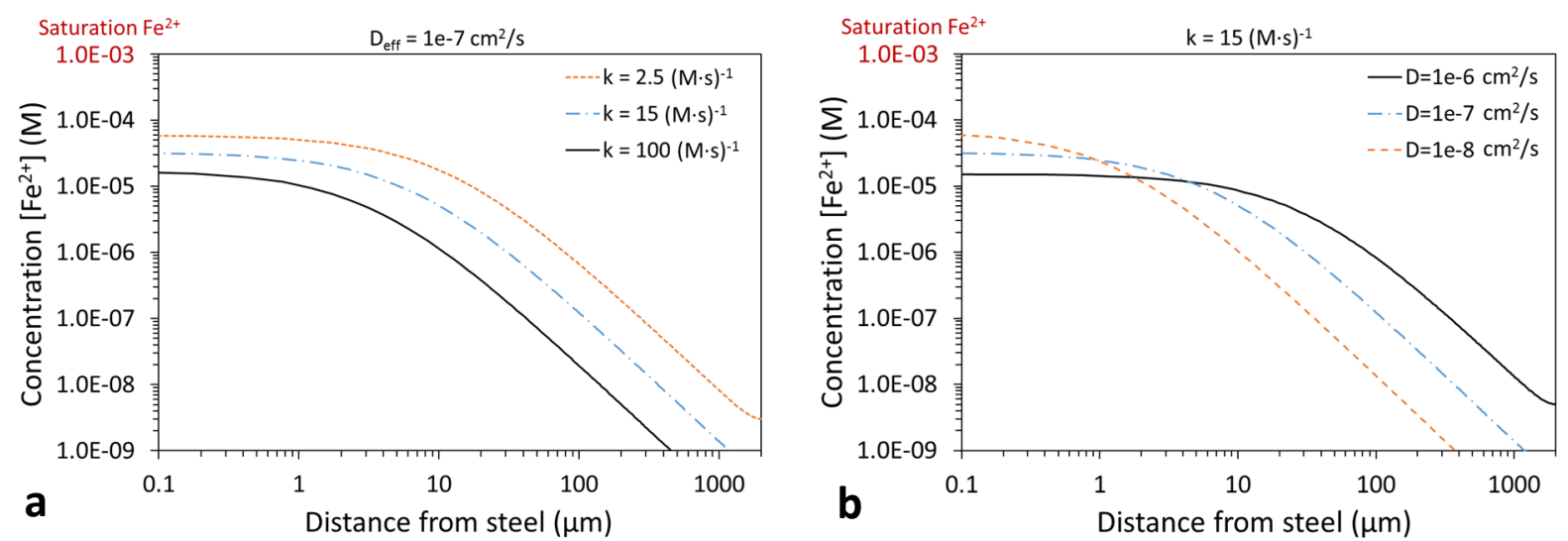

Figure 4. Concentration of dissolved $\mathrm{Fe}^{2+}$ in case different oxidation kinetic constants are used at fixed $\mathrm{D}_{\text {eff }}\left(1 \cdot 10^{-7} \mathrm{~cm}^{2} / \mathrm{s}\right.$, intermediate diffusion coefficient) (a) and if different effective diffusion coefficients are used at fixed $\mathrm{k}\left(15 \mathrm{M}^{-1} \cdot \mathrm{s}^{-1}\right.$, intermediate oxidation rate) (b) as a function of the distance from the steel surface $\left(a t t=50 \mathrm{~h}\right.$ ). As expected, the concentration of $\mathrm{Fe}^{2+}$ at the steel surface increases if the Fe ${ }^{2+}$ sinks, namely Fe ${ }^{2+}$ oxidation and $\mathrm{Fe}^{2+}$ diffusion, are slow. Nevertheless, in all here studied combinations, the $\mathrm{Fe}^{2+}$ concentration at the steel surface is always lower than the saturation threshold, thus, no $\mathrm{Fe}^{2+}$ precipitation is expected to occur.

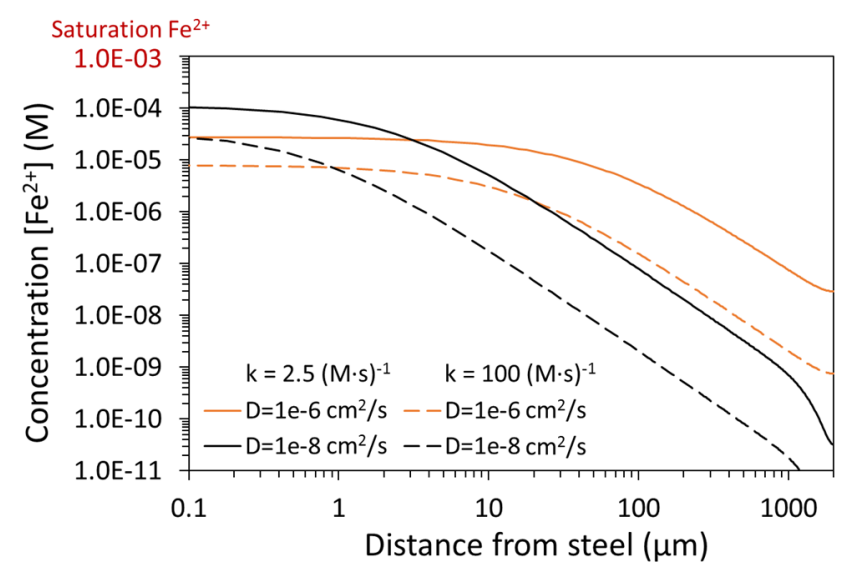

Figure 5. Concentration of dissolved $\mathrm{Fe}^{2+}$ as a function of the distance from the steel surface (at $\mathrm{t}=50 \mathrm{~h}$ ) in the extreme combinations of slow and fast rates of oxidation and diffusion, respectively. The Fe ${ }^{2+}$ concentration distant from the steel surface is strongly influenced by these parameters, while the concentration at the steel surface only varies over 1 order of magnitude. It is important to note, however, that even for the combination of slow $\mathrm{Fe}^{2+}$ oxidation and slow $\mathrm{Fe}^{2+}$ diffusion, the $\mathrm{Fe}^{2+}$ concentration never reaches the saturation level (still ca. 1 order of magnitude lower), thus, no $\mathrm{Fe}^{2+}$ precipitation is expected to occur. 
In engineering structures, the situation of multilayer rebars may lead to a macro-cell corrosion mechanism also for carbonation induced corrosion [42]. In this case the actual corrosion rate of the active areas can be increased, by the presence of the nearby passive rebar layers (in uncarbonated concrete). Due to area effects, however, the increase of corrosion rates compared to situations without additional cathodic rebar layers will be limited to a factor around 2-3 [42]. However, in view of the described model, this would primarily affect the input corrosion rate value; whereas the reaction and diffusion kinetics of $\mathrm{Fe}^{2+}$ would not be substantially affected, as they are only dependent on the pore solution $\mathrm{pH}$ and composition (chloride-free and $\mathrm{pH} 8$, in the present model) and on the transport properties (function of porosity). In fact, this model merely describes the reactive transport mechanism of $\mathrm{Fe}^{2+}$ released upon corrosion, regardless of the corrosion mechanism, this being either natural, macro-cell or artificially accelerated corrosion; provided the chloride-free condition is satisfied.

Finally, as mentioned, the actual concentration of $\mathrm{Fe}^{2+}$ at the steel surface appeared to be always clearly lower than the saturation threshold, but also higher than $1 \cdot 10^{-6} \mathrm{M}$. The latter is a common assumption made, e.g. in standard representations of the Pourbaix diagram of iron [43]. The actual concentration of $\mathrm{Fe}^{2+}$ at the steel surface depends on the $\mathrm{Fe}^{2+}$ oxidation rate and on the effective $\mathrm{Fe}^{2+}$ diffusion coefficient (function of the pore structure $[44,45]$ ), and on the corrosion rate. It is important to recognize, that the concentration of $\mathrm{Fe}^{2+}$ at the steel surface is not a constant, but, depending on the system and on the exposure conditions, may vary over a range of approx. 1 order of magnitude - or even more (Fig. 3-5 did not show the results for lower corrosion rates, where, however, the $\mathrm{Fe}^{2+}$ concentration can be even lower). This has major implications for the electrochemistry of steel in concrete, because the concentration of $\mathrm{Fe}^{2+}$ at the steel surface directly affects the reversible potential $\left(E_{a}\right)$ of the anodic reaction (eq. 1) described by the Nernst equation:

$$
E_{a}=E_{F e / F e^{2+}}^{r e v}=E_{F e / F e^{2+}}^{0}+\frac{R T}{n F} \ln \mathrm{Fe}^{2+}
$$

Here, $E_{F e, F e}^{0+}$ is the standard potential, $\mathrm{n}$ is the number of electrons exchanged, $\mathrm{F}$ the Faraday constant, $\mathrm{R}$ the gas constant, and $\mathrm{T}$ the temperature. A lower $\mathrm{Fe}^{2+}$ concentration depresses the reversible potential of the $\mathrm{Fe} / \mathrm{Fe}^{2+}$ electrode, which leads to an increase in the corrosion current density, as based on well-established considerations regarding corrosion kinetics [1]. It is beyond the scope of this letter to discuss the consequences of this in detail.

\section{Observations of distribution of corrosion products under natural corrosion conditions}

This section presents experimental evidences that products of carbonation-induced corrosion can travel far from the steel surface.

In the PhD thesis of Constantinou, microstructural analysis showed the distribution of corrosion products around the steel rebar [46] when the corrosion process occurred in natural exposure conditions, that is, without any acceleration of the corrosion process. According to these findings, the corrosion products could penetrate to distances up to the millimeter scale, without causing any concrete cracking.

Experiments carried out by the authors of this letter showed similar results. Thin carbonated mortar samples [47, 48], reinforced with steel wires, were exposed to different humidity environments where corrosion occurred naturally. Corrosion rates were in the range $1-4 \cdot 10^{-7} \mathrm{~A} / \mathrm{cm}^{2}$. After about one year, sections perpendicular to the steel wires, of samples exposed to $99 \% \mathrm{RH}$, were cut, polished and analyzed by SEM/EDX, in order to map the distribution of corrosion products. Fig. 5 shows an example of these analyses, showing how, in one year, the corrosion products spread to depths up to $0.5 \mathrm{~mm}$ within the mortar pore structure. It can be noticed how the products traveled around the aggregates of the mortar. It may be worth mentioning that the mortar was found uncracked at the time of terminating the corrosion experiments.

Unfortunately, such studies are rare in literature, especially in the context of carbonation-induced corrosion. Nevertheless, the experimental findings - both those reported by Constantinou [46] and the authors of this letter - support the modeling results, as they show how the precipitation of iron oxides can happen deep into the pore structure after $\mathrm{Fe}^{2+}$ formation at the steel surface.

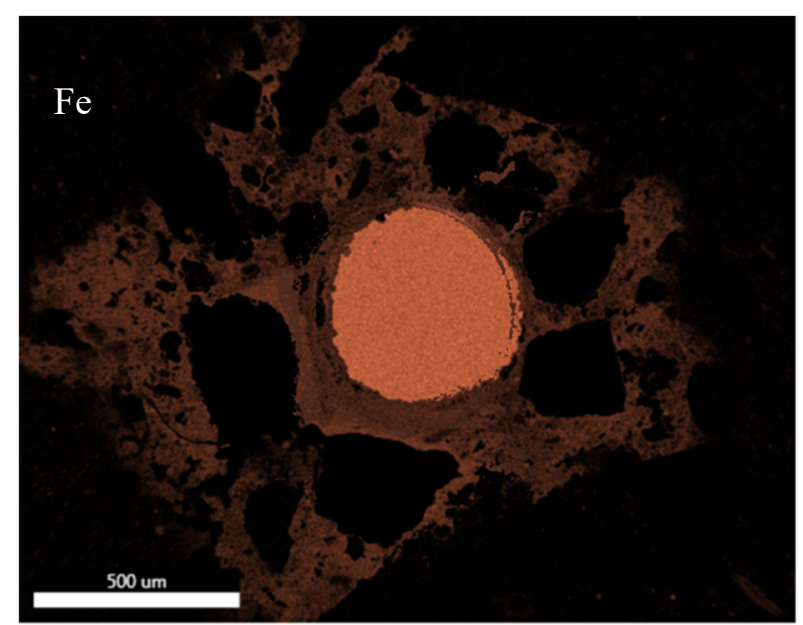

Figure 6. Iron mapping by SEM/EDX samples of a cut section of steel wire (diameter $0.5 \mathrm{~mm}$ ) embedded in a carbonated mortar (binder CEM II/B-M (T-LL), w/b ratio 0.6) and exposed to $99 \%$ RH for 1 year.

\section{Implications for accelerated corrosion testing}

Common experiments of corrosion-induced cracking, against which concrete-cracking models are calibrated, typically make use of corrosion accelerating techniques (e.g. impressed current methods). Corrosion rates are often significantly accelerated - 10 to 1000 times higher than the natural process [5-10] - which leads to a very fast release of $\mathrm{Fe}^{2+}$ at the steel surface. The impact of this on corrosion products formation can be illustrated with help of the model presented in this work. 
Considering a corrosion rate 100 times higher than $1 \cdot 10^{-6}$ $\mathrm{A} / \mathrm{cm}^{2}$ (the latter represent an extreme case under natural conditions), the ferrous ions produced by the process also are (eq. 9).

$$
J\left(\mathrm{Fe}^{2+}\right)=10^{-5} \mathrm{~mol} / \mathrm{s} \cdot \mathrm{m}^{2}
$$

By keeping all other model inputs identical with what was presented in section 3, the results shown in Fig. 7 are obtained. The $\mathrm{Fe}^{2+}$ concentration at the steel surface is now much higher than in conditions of natural corrosion (Figs. 45). In fact, the saturation level is now overcome, due to the accelerated corrosion process, causing, as a consequence, precipitation of the released ferrous ions at the steelconcrete interface directly in the form of $\mathrm{Fe}^{2+}$ rust. Further precipitation of $\mathrm{Fe}^{3+}$ products occurs at the highest possible rate (proportional to $\left[\mathrm{Fe}^{2+}\right]$, eq.7). Fig. 7 does not show that the concentration of $\mathrm{Fe}^{2+}$ in accelerated corrosion condition exceeds saturation because, as by step $B$ of the modeling (Fig. 2), $\mathrm{Fe}^{2+}$ is assumed to precipitate as soon as the saturation threshold is reached. Therefore the simulation cannot show a $\mathrm{Fe}^{2+}$ concentration as high as the saturation level. However, from the calculated formed $\mathrm{Fe}(\mathrm{OH})_{2}$ it becomes clear that $\mathrm{Fe}^{2+}$ precipitates under accelerated conditions (Fig. 7).

The formation of solid $\mathrm{Fe}(\mathrm{OH})_{2}$ (and $\mathrm{FeOOH}$ ) can block pores and thus further reduce the penetration of $\mathrm{Fe}^{2+}$ into the concrete matrix [10]. This was not considered in our model, but is expected to increase the $\mathrm{Fe}^{2+}$ concentration at the steel surface even more (leading to even more precipitation).
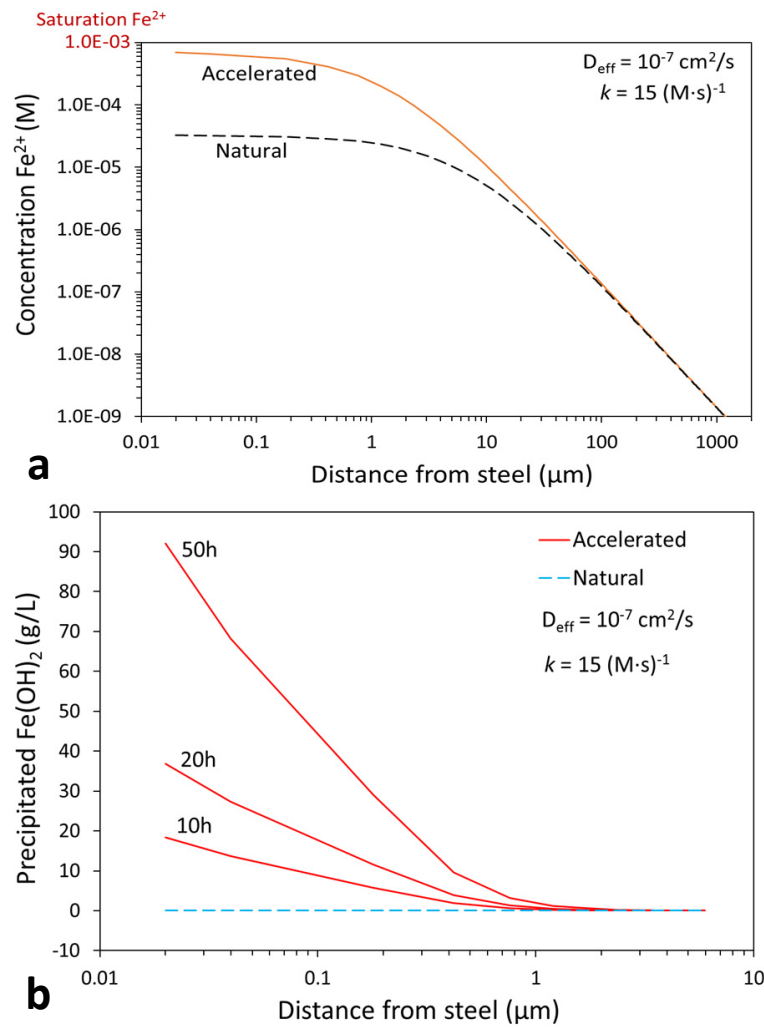

Figure 7. (a) $\mathrm{Fe}^{2+}$ concentration at the steady state, in case of accelerated corrosion testing in comparison with natural corrosion conditions. The accelerated process causes more than one order of magnitude higher $\mathrm{Fe}^{2+}$ concentration, at the steel surface, than what would occur in natural conditions, and leads to the precipitation of $\mathrm{Fe}(\mathrm{OH})_{2}$ and its accumulation over time, which would not occur in natural conditions (b).

\section{Conclusions}

This letter presented a conceptual model describing the fate of ferrous ions released during corrosion at the steel surface. The concentration of $\mathrm{Fe}^{2+}$ ions in the concrete pore solution is the result of a competition between the following processes: supply (anodic iron dissolution at the steel surface), oxidation, and transport of $\mathrm{Fe}^{2+}$. Depending on the actual conditions, the concentration of $\mathrm{Fe}^{2+}$ may or may not reach the saturation threshold, thus $\mathrm{Fe}(\mathrm{OH})_{2}$ may or may not precipitate. On the basis of numerical simulations and experimental results, the following major conclusions can be drawn:

- Under natural corrosion conditions, the saturation of $\mathrm{Fe}^{2+}$ is unlikely reached. This means that $\mathrm{Fe}^{2+}$ ions remain in dissolved state and may diffuse over considerable distances before being oxidized, in presence of oxygen, to $\mathrm{Fe}^{3+}$, in the form of which they precipitate.

- Under accelerated corrosion conditions (e.g. impressed anodic currents), the saturation of $\mathrm{Fe}^{2+}$ is likely exceeded at the steel surface. This means that $\mathrm{Fe}^{2+}$ immediately precipitates as $\mathrm{Fe}(\mathrm{OH})_{2}$, which prohibits further transport away from the steel surface.

- The distance to which corrosion products can diffuse under natural corrosion conditions before precipitating can be of the order of several 100 microns to millimeters. Thus, the pore volume being gradually filled with corrosion products can be considerably larger than in accelerated corrosion situations.

- As a consequence, expansive stresses giving rise to cracking can be reached at lower steel sectional area losses under accelerated test conditions, than under natural corrosion conditions.

- Models to predict corrosion-induced cracking may benefit from taking into account the $\mathrm{Fe}^{2+}$ reactive diffusion process here described. Such future research work would need to study in more detail the transport properties of ferrous ions in concrete, the impact of the microstructure at the steel-concrete interface, etc.

- Finally, the concentration of $\mathrm{Fe}^{2+}$ ions at the steel surface can vary over at least one order of magnitude, which has an influence on the electrochemistry of steel in concrete, ultimately affecting the corrosion kinetics. This could also be taken into account in mechanistic models for the corrosion rate in concrete.

\section{Acknowledgments}

Research supported by the Swiss National Foundation for Research (SNSF) project no. 154062 entitled "Formulation, use and durability of concrete with low clinker cements" is gratefully acknowledged. The authors would also like to 
thank Prof. Mette Geiker and Andres Belda Revert from NTNU Trondheim, for the pore solution extraction tests

\section{References}

[1] L. Bertolini, B. Elsener, P. Pedeferri, E. Redaelli, R.D. Polder Corrosion of steel in concrete: prevention, diagnosis, repair. John Wiley \& Sons (2013). https://doi.org/10.1002/9783527651696

[2] U. M. Angst, Challenges and opportunities in corrosion of steel in concrete. Mater Struct (2018) 51(1): 4 https://doi.org/10.1617/s11527-017-1131-6

[3] P.F. Marques, A. Costa, Service life of RC structures: Carbonation induced corrosion. Prescriptive vs. performance-based methodologies. Constr and Build Mater (2010) 24(3): 258265.https://doi.org/10.1016/j.conbuildmat.2009.08.039]

[4] P.F. Marques, A. Costa, F. Lanata, Service life of RC structures: chloride induced corrosion: prescriptive versus performancebased methodologies. Mater Struct (2010) 45(1-2): 277-296. https://doi.org/10.1617/s11527-011-9765-2

[5] A. Michel, B.J. Pease, A. Peterová, M.R. Geiker, H. Stang, A.E.A Thybo, Penetration of corrosion products and corrosion-induced cracking in reinforced cementitious materials: Experimental investigations and numerical simulations. Cem Concr Compos (2014) 47: 75-86 https://doi.org/10.1016/j.cemconcomp.2013.04.011

[6] B. Šavija, M. Luković, S.A.S. Hosseini, J. Pacheco, E. Schlangen, Corrosion induced cover cracking studied by X-ray computed tomography, nanoindentation, and energy dispersive $\mathrm{X}$-ray spectrometry (EDS), Mater Struct (2015) 47(7): 2043-2062. https://doi.org/10.1617/s11527-014-0292-9

[7] C. Lu, W. Jin, R. Liu, Reinforcement corrosion-induced cover cracking and its time prediction for reinforced concrete structures, Corros Sci (2011) 53(4): 1337-1347. https://doi.org/10.1016/i.corsci.2010.12.026

[8] C. Alonso, C. Andrade, J. Rodriguez, J.M. Diez, Factors controlling cracking of concrete affected by reinforcement corrosion. Mater $\begin{array}{llll}\text { Struct } & \text { (1998) } & \text { 31(7): }\end{array}$ https://doi.org/10.1007/BF02480466

[9] C. Andrade, C. Alonso, F.J. Molina, Cover cracking as a function of bar corrosion: Part I-Experimental test. Mater Struct (1993) 26(8): 453-464. https://doi.org/10.1007/BF02472805

[10] Y. Zhao, H. Ding, W. Jin, Development of the corrosion-filled paste and corrosion layer at the steel/concrete interface. Corros Sci (2014) 87: 199-210. https://doi.org/10.1016/j.corsci.2014.06.032

[11] U. Angst, B. Elsener, A. Jamali, B. Adey, Concrete cover cracking owing to reinforcement corrosion-theoretical considerations and practical experience. Mater Corros (2012) 63(12): 1069-1077. https://doi.org/10.1002/maco.201206669

[12] K. Bhargava, A.K. Ghosh, Y. Mori, S. Ramanujam, Model for cover cracking due to rebar corrosion in RC structures. Eng Struct (2006) 28(8): 1093-1109. https://doi.org/10.1016/j.engstruct.2005.11.014

[13] C. Fahy, S.J. Wheeler, D. Gallipoli, P. Grassl, Corrosion induced cracking modelled by a coupled transport-structural approach. Cem Concr Res (2017) 94: 24-35.

https://doi.org/10.1016/j.cemconres.2017.01.007

[14] C. Cao, M.M.S. Cheung, B.Y.B. Chan, Modelling of interaction between corrosion-induced concrete cover crack and steel corrosion rate. Corros Sci (2013) 69: 97-109. https://doi.org/10.1016/j.corsci.2012.11.028

[15] L. Chernin D.V. Val, Prediction of corrosion-induced cover cracking in reinforced concrete structures. Constr Build Mater (2011) 25(4): 1854-1869. https://doi.org/10.1016/j.conbuildmat.2010.11.074

[16] Y. Zhao, J. Dong, Y. Wu, W. Jin, Corrosion-induced concrete cracking model considering corrosion product-filled paste at the concrete/steel interface. Constr Build Mater (2016) 116: 273-280. https://doi.org/10.1016/j.conbuildmat.2016.04.097

[17] A. Jamali, U. Angst, B. Adey, B. Elsener, Modeling of corrosioninduced concrete cover cracking: A critical analysis. Constr Build Mater (2013) 42: 225-237. https://doi.org/10.1016/j.conbuildmat.2013.01.019

[18] K. K. Sagoe-Crentsil, F. P. Glasser, "Green rust", iron solubility and the role of chloride in the corrosion of steel at high $\mathrm{pH}$. Cem Concr Res (1993) 23(4): 785-791.

https://doi.org/10.1016/0008-8846(93)90032-5
[19] H.S. Wong, Y.X. Zhao, A.R. Karimi, N.R. Buenfeld, W.L. Jin, On the penetration of corrosion products from reinforcing steel into concrete due to chloride-induced corrosion. Corros Sci (2010) 52(7): 2469-2480. https://doi.org/10.1016/j.corsci.2010.03.025

[20] R.M. Cornell, U. Schwertmann, The iron oxides: structure properties, reactions, occurrences and uses. John Wiley \& Sons 2003. https://doi.org/10.1002/3527602097

[21] W.H. Walker, A.M. Cederholm, L.N. Bent, The corrosion of iron and steel. J Am Chem Soc (1907) 29(9): 1251-1264. https://doi.org/10.1021/ja01963a001

[22] D. A. Hausmann, Steel corrosion in concrete-How does it occur? Materials Protection (1967)

[23] R.A. Antunes, R.U. Ichikawa, L.G. Martinez, I. Costa, Characterization of corrosion products on carbon steel exposed to natural weathering and to accelerated corrosion tests. Int J Corros (2014). https://doi.org/10.1155/2014/419570

[24] M. Stratmann, The Atmospheric Corrosion of Iron-A Discussion of the Physico-Chemical Fundamentals of this Omnipresent Corrosion Process. Berichte der Bunsengesellschaft für physikalische Chemie (1990) 94(6): 626-639. https://doi.org/10.1002/bbpc.19900940603

[25] K. Suda, S. Misra, K. Motohashi, Corrosion products of reinforcing bars embedded in concrete. Corr Sci (1993) 35(5-8): 1543-1549. https://doi.org/10.1016/0010-938X(93)90382-Q

[26] R. Vera, M. Villarroel, A.M. Carvajal, E. Vera, C. Ortiz, Corrosion products of reinforcement in concrete in marine and industrial environments," Mater Chem Phys (2009) 114(1): 467-474. https://doi.org/10.1016/j.matchemphys.2008.09.063

[27] W. L. Lindsay, Chemical equilibria in soils. John Wiley and Sons (1979).

[28] B. Morgan, O. Lahav, The effect of $\mathrm{pH}$ on the kinetics of spontaneous $\mathrm{Fe}$ (II) oxidation by $\mathrm{O} 2$ in aqueous solution-basic principles and a simple heuristic description. Chemosphere (2007) 68(11): 2080-2084 https://doi.org/10.1016/j.chemosphere.2007.02.015

[29] P.C. Singer, W. Stumm, The solubility of ferrous iron in carbonatebearing waters. J Am Water Works Assoc (1970) 62(3): 198-202. https://doi.org/10.1002/j.1551-8833.1970.tb03888.x

[30] M. Stefanoni, U. Angst, B. Elsener, Corrosion rate of carbon steel in carbonated concrete - A critical review. Cem Concr Res (2018) 103: 35-48. https://doi.org/10.1016/j.cemconres.2017.10.007

[31] M. Stefanoni, U. Angst, B. Elsener, Electrochemistry and capillary condensation theory reveal the mechanism of corrosion in dense porous media. Sci Rep (2018) 8. https://doi.org/10.1038/s41598018-25794-x

[32] U. M. Angst et al., The steel-concrete interface. Mater Struct (2017) 50(2): 143. https://doi.org/10.1617/s11527-017-1010-1

[33] W. Stumm, G.F. Lee, Oxygenation of ferrous iron. Ind Eng Chem (1961) 53(2): 143-146. https://doi.org/10.1021/ie50614a030

[34] W. Sung, J.J. Morgan, Kinetics and product of ferrous iron oxygenation in aqueous systems. Environ Sci Technol (1980) 14(5): 561-568. https://doi.org/10.1021/es60165a006

[35] A.N. Pham, T.D. Waite, Oxygenation of Fe (II) in natural waters revisited: Kinetic modeling approaches, rate constant estimation and the importance of various reaction pathways. Geochimica et Cosmochimica Acta (2008) 72(15): 3616-3630.

https://doi.org/10.1016/j.gca.2008.05.032

[36] Q. Pu, L. Jiang, J. Xu, H. Chu, Y. Xu, Y. Zhang, Evolution of pH and chemical composition of pore solution in carbonated concrete. Constr Build Mater (2012) 28(1): 519-524 https://doi.org/10.1016/j.conbuildmat.2011.09.006

[37] X. Liu, D. Niu, X. Li, Y. Lv, Q. Fu, Pore Solution pH for the Corrosion Initiation of Rebars Embedded in Concrete under a Long-Term Natural Carbonation Reaction. App Sci (2018) 8(1): 128. https://doi.org/10.3390/app8010128

[38] C. Andrade, Calculation of chloride diffusion coefficients in concrete from ionic migration measurements. Cem Concr Res (1993) 23(3): 724-742 https://doi.org/10.1016/0008-8846(93)90023-3

[39] S. Zofia, Z. Adam, Theoretical model and experimental tests on chloride diffusion and migration processes in concrete. Proc Eng (2013) 57: 1121-1130 https://doi.org/10.1016/i.proeng.2013.04.141

[40] V. Elfmarkova, P. Spiesz, H.J.H. Brouwers, Determination of the chloride diffusion coefficient in blended cement mortars. Cem Concr Res (2015) 78: 190-199.

https://doi.org/10.1016/i.cemconres.2015.06.014 
[41] P. Spiesz, H.J.H. Brouwers, The apparent and effective chloride migration coefficients obtained in migration tests. Cem Concr Res (2013) 48: 116-127.

https://doi.org/10.1016/j.cemconres.2013.02.005

[42] M. G. Sohail, S. Laurens, F. Deby, J. P. Balayssac, Significance of macrocell corrosion of reinforcing steel in partially carbonated concrete: numerical and experimental investigation. Mater Struct (2015) 48(1-2): 217-233.

https://doi.org/10.1617/s11527-013-0178-2

[43] N. De Zoubov, J.V. Pourbaix, Atlas d'équilibres électrochimiques, Paris, 1963.

[44] T.C. Powers, Structure and physical properties of hardened Portland cement paste. J Am Ceram Soc (1958) 41(1): 1-6. https://doi.org/10.1111/j.1151-2916.1958.tb13494.x

[45] R.A. Patel, J. Perko, D. Jacques, G. De Schutter, G. Ye, K. Van Bruegel, Effective diffusivity of cement pastes from virtual microstructures: Role of gel porosity and capillary pore percolation. Constr Build Mater (2018) 165: 833-845. https://doi.org/10.1016/i.conbuildmat.2018.01.010

[46] A. Constantinou, The corrosion of steel reinforcement in carbonated concrete. London, 1995.

[47] M. Stefanoni, U. Angst, B. Elsener, A New Setup for Rapid Durability Screening of New Blended Cements. in Concrete Innovation Conference (CIC2017), Trosmo, 2017.

[48] M. Stefanoni, U. Angst, B. Elsener, Innovative sample design for corrosion rate measurement in carbonated concrete. in 11th annual International Concrete Sustainability Conference (2016 ICSC), Washington DC, 2016. 